\title{
Transportes e Dinâmicas Econômicas no Desenvolvimento do Maranhão
}

\author{
Transport and Economic Dynamics in the Development of Maranhão
}

Transportes y Dinámicas Económicas en el Desarrollo de Maranhão

\author{
Allison Bezerra Oliveira ${ }^{1}$ \\ https://orcid.org/0000-0003-0320-5661 \\ Diego Armando de Sousa Paz ${ }^{2}$ \\ https://orcid.org/0000-0001-7360-6554 \\ Maria do Rosário Sá Araújo ${ }^{3}$ \\ https://orcid.org/0000-0003-2259-8085
}

RESUMO: O presente artigo tem por objetivo discutir as relações entre a infraestrutura de transportes e as transformações econômicas que se sucederam no Maranhão a partir do fim do século XX. Partese do ponto central de que os transportes são elementos fundamentais dos movimentos de "modernização" econômica vividos pelo estado desde então, como a expansão da fronteira agrícola, a implantação de grandes projetos minerometalúrgicos e, mais recentemente, agroindustriais. Para analisar tais relações, foram utilizados dados da Indústria Brasileira de Árvores, Empresa Maranhense de Administração Portuária, Departamento Nacional de Infraestrutura de Transportes, Departamento Nacional de Trânsito e Instituto Brasileiro de Geografia e Estatística, além de fotografias de acervo resultantes de pesquisa de campo. Os resultados indicam que os movimentos de "modernização econômica", apoiados por ações estatais e investimentos nos modais rodoviário e ferroportuário, contribuíram para a estruturação de um capitalismo "moderno" no estado, com vistas à produção de commodities minerais e agrícolas para o mercado externo.

PALAVRAS-CHAVE: Transportes. Commodities. Agro-minero-exportação. Maranhão.

ABSTRACT: This article aims to discuss the relations between transport infrastructure and the economic transformations that have followed in Maranhão since the end of the 20th century. It starts

\footnotetext{
${ }^{1}$ Doutorado em Geografia pela Universidade Federal de Pernambuco. Professor Adjunto do Curso de Geografia da Universidade Estadual da Região Tocantina do Maranhão. E-mail: allisonbzr@gmail.com.

2 Graduando em Geografia pela Universidade Estadual da Região Tocantina do Maranhão. E-mail: d.armando146@hotmail.com.

${ }^{3}$ Master en Ciencias de la Educación - Universidad Politecnica y Artistica del Paraguay e Mestrado em Ciências Políticas e Administração Pública - American Wold University. Professora da Universidade Estadual do Maranhão. E-mail: maria.araujo@uemasul.edu.br.
} 
from the central point that transports are fundamental elements of the economic "modernization" movements experienced by the state since then, such as the expansion of the agricultural frontier, the implementation of large mining and, more recently, agro-industrial projects. To analyze such relations, we used data from the Brazilian Tree Industry, Empresa Maranhense de Administração Portuária, Departamento Nacional de Infraestrutura de Transportes, Departamento Nacional de Trânsito and Instituto Brasileiro de Geografia e Estatística, in addition to photographs of collections resulting from field research. The results indicate that "economic modernization" movements, supported by state actions and investments in road and rail modes, contributed to the structuring of a "modern" capitalism in the state, with a view to the production of mineral and agricultural commodities for the foreign market.

KEYWORDS: Transport. Commodities. Agro-mining-export. Maranhão.

RESUMEN: El presente artículo tiene por objeto discutir las relaciones entre la infraestructura de transportes y las transformaciones económicas que se han sucedido en Maranhão desde finales del siglo XX. Se parte del punto central de que los transportes son elementos fundamentales de los movimientos de "modernización" económica vividos por el estado desde entonces, como la expansión de la frontera agrícola, la implantación de grandes proyectos mineros metalúrgicos y, más recientemente, agroindustriales. Para analizar dichas relaciones, se utilizaron datos de la Industria Brasileña de Árboles, Empresa Maranhense de Administración Portuaria, Departamento Nacional de Infraestructura de Transportes, Departamento Nacional de Tránsito y Instituto Brasileño de Geografía y Estadística, además de las fotografías de acervo resultantes de la investigación de campo. Los resultados indican que los movimientos de "modernización económica", apoyados por acciones estatales e inversiones en los modales de carretera y ferroportuario, contribuyeron para la estructuración de un capitalismo "moderno" en el estado, con vistas a la producción de commodities minerales y agrícolas para el mercado exterior.

PALABRAS CLAVE: Transportes. Commodities. Agro-minero-exportación. Maranhão.

\section{INTRODUÇÃO}

Até meados de 1930, o mercado brasileiro era pouco integrado, constituído de pequenos núcleos econômicos quase exclusivamente voltados para a exportação de produtos do setor primário, com poucas exceções, como as cidades de São Paulo e do Rio de Janeiro (PRADO JÚNIOR, 1945).

Pode-se afirmar que, até esse período, o país ainda vivia um processo de transição de seu regime de trabalho - da escravidão para o trabalho assalariado - pois embora o trabalho compulsório tenha sido oficialmente extinto em 1888, a consolidação das relações capitalistas de produção só se deu na segunda metade do século $X X$. Até que se consolidassem tais relações, havia formas híbridas de trabalho livre, de caráter précapitalista, vivenciadas principalmente no campo. Estas, dentre outras questões, contribuíram para a demora na modernização produtiva brasileira e a consequente instalação do capitalismo tardio no país (MESQUITA, 2011; SUZIGAN, 2000).

Os anos que sucederam a década de 1930 foram fundamentais para o desenvolvimento do capitalismo no país. Após a crise da bolsa de 1929, o Brasil passou por 
um período de transição do capital agroexportador, centrado no café, para uma economia industrial urbana, como resposta às dificuldades de importação de produções essenciais. Nesse momento, o país adotou uma postura intervencionista, com políticas de cunho desenvolvimentista que buscavam não apenas reestruturar o capitalismo, mas permitir a modernização produtiva das regiões e integrar as regiões periféricas (Centro-Oeste, Norte e Nordeste) ao centro hegemônico do país, o Centro-Sul, por meio da movimentação de alimentos, matéria-prima e serviços (MESQUITA, 2011).

Governos como o de Getúlio Vargas (1930-1945), Juscelino Kubitschek (1956-1961) e os governos militares (1964-1985) potencializaram os processos de industrialização e expansão das infraestruturas de transportes com vistas à agroexportação. No Regime Militar, a especialização na produção de matéria-prima recebeu um imenso aporte por meio dos grandes projetos, principalmente no fim da década de 1970 e início da de 1980.

Nesse contexto, o Maranhão foi inserido em um novo ciclo de modernização periférica. Até então predominantemente rural, o estado, cuja economia era centrada na agricultura (sobretudo produção de arroz), adentrou um ciclo, a priori, baseado na economia de fronteira, e posteriormente, no modelo de enclave de grandes projetos minerometalúrgicos baseados na exportação.

Nesse cenário de transformações e "integração" econômica do estado, os transportes tiveram um importante papel, destacando-se as infraestruturas de transportes como agentes de mobilidade dos fluxos de capital necessários para o pleno funcionamento da dinâmica produtiva: peças, maquinários, trabalhadores, matéria-prima, serviços etc. Dessa forma, no fim do século $X X$, os transportes viabilizaram os estágios recentes de desenvolvimento econômico do Maranhão.

Pode-se dizer, portanto, que se os movimentos econômicos ocorridos no Maranhão a partir desse período - em especial a fronteira agrícola e os grandes projetos agroindustriais — são responsáveis pela estruturação de um capitalismo "moderno" no estado, isso só foi possível graças à expansão dos modais de transporte (rodoviário e ferroportuário).

Assim, o objetivo do presente artigo é discutir as relações entre a infraestrutura de transportes e as transformações econômicas que se sucederam no Maranhão viabilizadas por essas estruturas. Parte-se do ponto central de que os transportes são elementos fundamentais dos movimentos de "modernização" econômica vividos pelo estado a partir dos anos de 1970.

Delimitou-se o estado do Maranhão, região Nordeste do Brasil, e a década de 1970 como recortes espacial e temporal desta pesquisa. Além disso, a construção da rodovia Belém-Brasília também foi estabelecida como marco das análises empreendidas. Foram utilizados dados da Indústria Brasileira de Árvores (2020); Empresa Maranhense de Administração Portuária (2020); BRASIL (2016); Departamento Nacional de Trânsito (2020) 
e IBGE $(2010,2020)$ para construir mapas e gráficos; fotografias de acervo resultantes de pesquisa de campo também foram usadas, permitindo conectar as relações quase indissociáveis entre alguns estágios de transformação econômica no Maranhão e a modernização dos transportes.

A primeira parte do artigo discute a importância da rodovia Belém-Brasília para a integração de mercadorias e matéria-prima entre o Maranhão e o centro-sul do país. A segunda parte aborda os grandes projetos industriais, empreendidos a contar da década de 1970; o desenvolvimento portuário, a partir da modernização do Porto do Itaqui, e ferroviário, com o Grande Projeto Carajás, no Pará, que permitiu conectar o transporte de minério pela região através da malha ferroviária, dando início ao grande estágio de exportação estadual. Por último, a terceira parte discute as novas reestruturações econômicas locais, provocadas pela produção de pasta de celulose, e a dinâmica de integração modal desencadeada pelo agente agroindustrial instalado no estado.

\section{FRONTEIRA AGRÍCOLA, BELÉM-BRASílIA E A “INTEGRAÇÃO" NACIONAL DO MARANHÃO}

Na segunda metade do século XX, o Maranhão foi inserido em um novo processo de "integração" econômica e regional. Orientado pela centralidade política do centro-sul do Brasil, esse processo direcionou as políticas macroeconômicas para a construção de infraestruturas de transportes, visando integrar as regiões e promover crescimento econômico com base num ideário de conexão entre as regiões, com vistas a produzir e transportar matéria-prima pelo país recém-industrializado.

Nessa época, a economia de fronteira, característica da dinâmica socioeconômica brasileira, foi intensificada pelo Estado a partir da expansão da materialidade técnica das infraestruturas de transportes, como rodovias, ferrovias e portos. Neste contexto, houve uma aceleração na transformação espacial brasileira, sobretudo orientada para exploração e transporte de matéria-prima para as indústrias de bens de produção e de consumo.

O projeto Marcha para o Oeste, dos governos de Getúlio Vargas (1930-1945 e 1951 1954), fruto da política de substituição de importações, que vislumbrava promover a indústria nacional através da fabricação e consumo de manufaturas e insumos fundamentais ao Brasil, refletiu em programas de ampliação de setores essenciais para a atividade industrial: infraestrutura de transporte rodoviário, energia e comunicações.

De modo semelhante, o Plano de Metas do governo de Juscelino Kubitschek (19561961), encerrado no governo de João Goulart (1961-1964), estabeleceu um dos mais importantes programas de modernização e industrialização do Brasil, traçando um 
ambicioso conjunto de objetivos setoriais que daria continuidade ao processo de substituição de importações. Em meio a investimentos em setores como siderurgia, comunicações, energia e agricultura, o rodoviarismo estabeleceu-se como via dos principais fluxos de bens e serviços.

As rodovias resultaram de estratégias de integração e desenvolvimento nacional. Ao mesmo tempo, atenderam às necessidades do mercado internacional do petróleo por meio da expansão da indústria automobilística, de combustíveis, pneus e asfalto. E o principal: possibilitaram a mobilidade de capitais pelo país, sobretudo matéria-prima (MESQUITA et al., 2015; MOTTA, 2004).

As estradas se tornaram, assim, a base material para a aceleração e o reordenamento de fluxos e processos de ocupação na Amazônia Legal (como a maranhense), especialmente a partir do fim da década de 1970, sob o ideário da fronteira agrícola. Esse pensamento, fortemente amparado por programas estatais de desenvolvimento regional e órgãos governamentais - como a Superintendência do Desenvolvimento da Amazônia (Sudam) e a Superintendência do Desenvolvimento do Nordeste (Sudene) - , permitiu o aprofundamento das bases capitalistas hoje presentes na fronteira agrícola brasileira: frentes de agricultura comercial impulsionadas por mercados de núcleo dinâmico da economia e afetadas por políticas de incentivo e pela expansão da infraestrutura na fronteira (SICSÚ; LIMA, 2000).

Nesse momento, foi criada a rodovia popularmente conhecida como Belém-Brasília, que recebeu o nome de Rodovia Bernardo Sayão ou BR-010, também chamada de Rodovia Transbrasiliana quando considerado todo o trecho do Rio Grande do Sul ao Pará. Sua construção permitiu a modernização de diversas cidades e a dinamização econômica destacando-se o setor de serviços, o extrativismo e a agropecuária - , principalmente na porção tocantina da Belém-Brasília. A rodovia é o principal eixo de ligação rodoviária da região Norte com o restante do país. Em Goiás e parte do Tocantins, recebe a designação de BR-153; no Pará, de BR-010 e BR-316, e no Maranhão, de BR-010. Ainda no Tocantins, ela também é chamada de BR-226.

A estrada atendeu a uma demanda de integração do mercado nacional, motivo da política de Estado que viabilizou a construção de Brasília durante o governo Kubitschek. 0 simbolismo do transporte rodoviário foi assim descrito pelo então presidente:

Lançadas as bases de Brasília, era tempo de estender o olhar pelo mapa e visualizar, mais uma vez, a presença do grande cruzeiro de estradas, que faria a integração nacional. Era a velha obsessão que me perseguia. A ligação do Brasil por dentro! Quando sobrevoava a Amazônia, figurava na mente a linha reta que vincularia Brasília a Belém (KUBITSCHEK, 2000, p. 97). 
Considerando as ambições do projeto de modernização do país e a demanda por maior circulação de matéria-prima, insumos e mercadorias, tornou-se fundamental a construção de uma rodovia longitudinal que ligasse a capital ao norte do país, cortando as extensas áreas de floresta amazônica e cerrado. Os Decretos $n^{\circ} 43.730$, de 15 de maio de 1958, e $n^{\circ}$ 43.909, de 16 de junho de 1958, criaram a Comissão Executiva da Rodovia Belém-Brasília (Rodobrás) e estabeleceram normas especiais para a sua construção (ARRAIS; CASTILHO; AURÉLIO NETO, 2016).

O processo de construção da rodovia Belém-Brasília (Figura 1), iniciado em 1950 e concluído em 1974, estimulou que pontos de apoio emergissem com status de cidade, provocando a fragmentação e o surgimento de centralidades interurbanas nas áreas que margeiam a estrada, a exemplo de Imperatriz, Estreito, Carolina, Itinga do Maranhão, Açailândia e Porto Franco, no Maranhão, além de Paragominas e Dom Eliseu, no Pará.

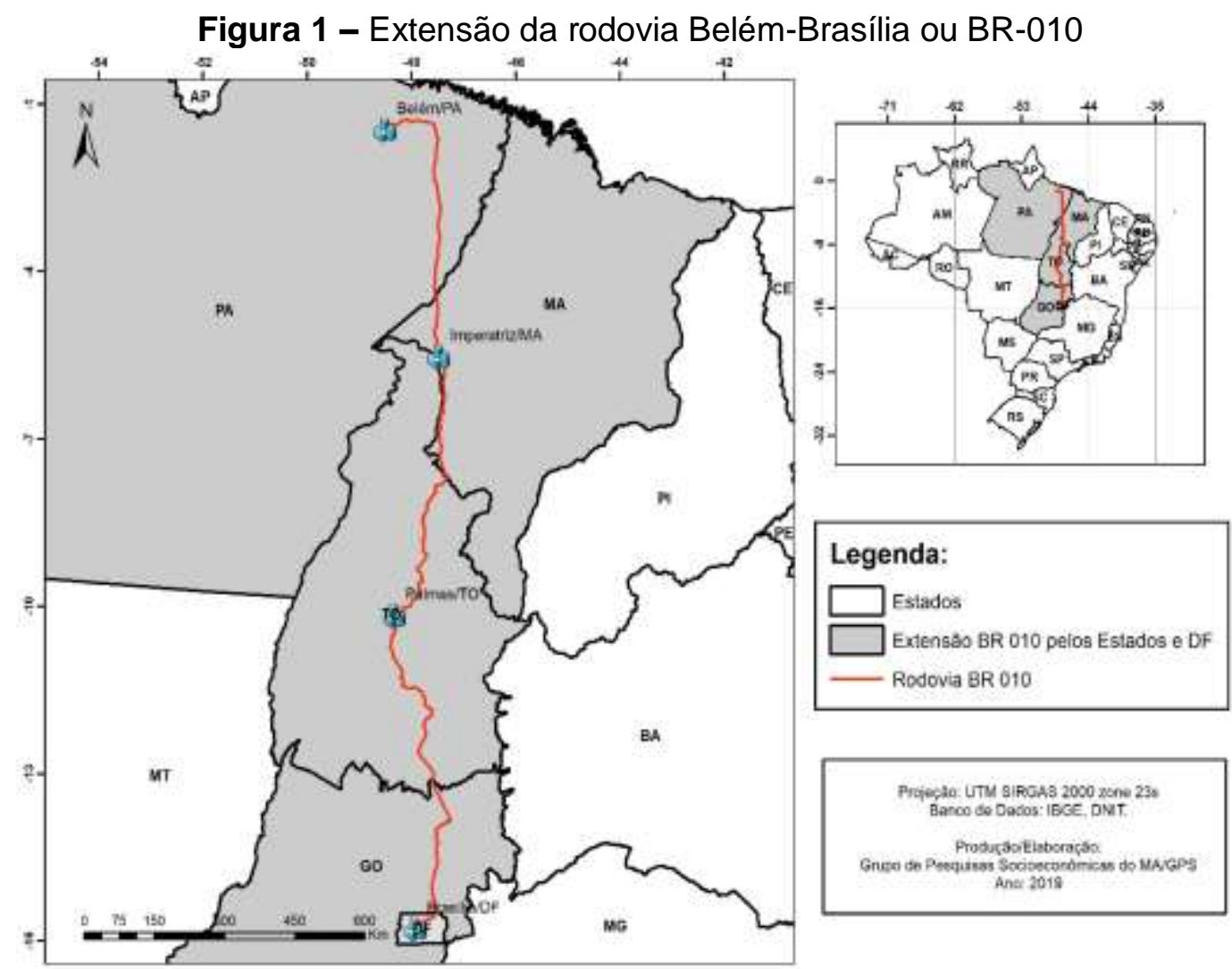

Fonte: Brasil (2016); IBGE (2010).

A rodovia Belém-Brasília permitiu que insumos, bens e mercadorias fossem transportados com maior facilidade, acelerando a mecanização do campo e o aumento na produção agrícola e na pecuária. Atraiu também a implantação de empresas de diversos segmentos que ampliaram a oferta de serviços na região. Nesse momento, houve, 
inegavelmente, maior penetração de capitais na região, sobretudo tendo em vista a integração regional, nesse caso, centrada na mobilidade de matéria-prima.

A partir disso, as transformações que se sucederam no espaço maranhense, principalmente às margens da BR-010, permitiram o avanço das frentes especulativas de grandes famílias e empresas latifundiárias - sobretudo as frentes baseadas na grilagem de terras - , consolidando a modernização capitalista da fronteira agrícola, o que abre a possibilidade de inserção do grande capital público e privado da atividade industrial, em especial os empreendimentos de base minerometalúrgica.

\section{GRANDES PROJETOS INDUSTRIAIS, DESENVOLVIMENTO FERROPORTUÁRIO E OS CAMINHOS PARA EXPORTAÇÃO}

Ainda na década de 1970, mais precisamente em 1972, foram concluídas as primeiras obras de construção do Porto do Itaqui, cais portuário localizado no Maranhão. A construção teve início em 1966, executada pela empresa brasileira Serveng-Civilsan. Em 1973, foi criada a então Companhia Docas do Maranhão (Codomar), para administrar as novas instalações, isto é, um cais com 637 metros de extensão, entregue ao tráfego em 4 de julho de 1974, iniciando as operações no Porto do Itaqui. Foram feitas modernizações nos anos de 1976, 1994 e 1999, que ampliaram a infraestrutura portuária, expandindo a extensão do cais, o quantitativo de berços e o acesso a áreas mais profundas. Por último, no ano de 2000, foi criada a Empresa Maranhense de Administração Portuária (EMAP).

Em 1974, o governo do estado do Maranhão construiu o porto do Itaqui em um sítio com condições geográficas estratégicas como: acesso a uma profundidade natural mínima de 27 metros, largura aproximada de 1,8 quilômetros. Além de localização favorável a outros portos brasileiros, principalmente no Nordeste, e ao mercado exterior, como a proximidade com o canal do Panamá.

A construção do Porto do Itaqui foi elemento relevante na inserção do Maranhão visto como território da Amazônia Legal brasileira - no II Plano Nacional de Desenvolvimento, do Governo Militar, o chamado II PND (1975 -1979), que, entre outros aspectos, visava a modernização de espaços considerados vazios com potencial produtivo.

Na década de 1980, seguinte à construção do porto e às políticas da década anterior, uma política de desenvolvimento da Amazônia Oriental expressou-se pelos grandes projetos da então Companhia Vale do Rio Doce (CVRD), centrada no minério de ferro, e do Consórcio de Alumínio do Maranhão (Alumar), focado na bauxita e na produção de lingotes de alumínio para exportação. O consumo industrial de energia elétrica elevou-se intensamente com os empreendimentos da CVRD e da Alumar, que requereram a construção da Usina Hidrelétrica de Tucuruí, no estado do Pará. 
Esses grandes projetos representaram transformações espaciais significativas na região e permitiram ao Maranhão - mesmo na década perdida brasileira - aumentar o seu Produto Interno Bruto. Mais do que isso, foi a partir dessa reorientação econômica dos grandes projetos que houve um novo ciclo de modernização técnica das infraestruturas de transportes, resultando na integração dos modais de transportes estaduais.

A ampliação da capacidade produtiva e o crescimento econômico evidenciados pelo Maranhão frente o avanço da infraestrutura ferroportuária e os grandes projetos industriais foram, de certa forma, cooptados pelas grandes oligarquias políticas que alardearam tais avanços como uma redenção socioeconômica para o estado. De acordo com essa hipótese, a partir daquele momento, o Maranhão entraria em uma rota crescente de desenvolvimento e industrialização.

Porém, isso não ocorreu, e a inserção do Maranhão nos fluxos de comércio global — dominado pelas multinacionais, por meio dos grandes projetos e do transporte de commodities - contribuiu para a tipificação do modelo de enclave na economia regional, além do aumento da concentração de terra em nome de latifundiários e empresas agrícolas (MESQUITA et al., 2015).

A partir disso, grandes grupos se instalaram em diversas regiões do estado, a exemplo de empresas nacionais e multinacionais como Cargill Agrícola S/A, Bunge Alimentos S/A, ABC INCO S/A, CEAGRO Agronegócios, Fazenda Parnaíba S/A, SLC Agrícola S/A, Weisil Agrícola Ltda. e Multigrain S/A que controlam o agronegócio no Maranhão.

A inserção do Maranhão nos fluxos de comércio global ocorreu em paralelo à expansão do Projeto Carajás e sua demanda por escoamento da produção, o que resultou na construção da Estrada de Ferro Carajás, também conhecida como Ferrovia CarajásItaqui (Figura 2), inaugurada em 1985. Trata-se de uma ferrovia de 892 quilômetros (destes, 695 quilômetros no Maranhão e 197 quilômetros no Pará), que percorre, atualmente, 21 municípios no setor noroeste. Resultou, também, na implantação de dois portos especializados, próximos ao Porto do Itaqui; na ampliação da rede de energia elétrica e na construção dos primeiros 100 quilômetros da Ferrovia Norte-Sul (entre Açailândia e Imperatriz), entregues em 1989.

Embora a Estrada de Ferro Carajás seja a maior ferrovia de transporte de passageiros em operação no Brasil - possuindo cinco estações, 10 paradas e percorrendo os municípios maranhenses de São Luís, Santa Inês e Açailândia, e os paraenses de Marabá e Parauapebas - é no transporte de mercadorias, sob a forma de commodities minerais (e, mais tarde, agrícolas), que se encontra o principal sentido de sua construção e interligação com outros modais. 
Figura 2 - Estrada de Ferro Carajás e municípios de abrangência

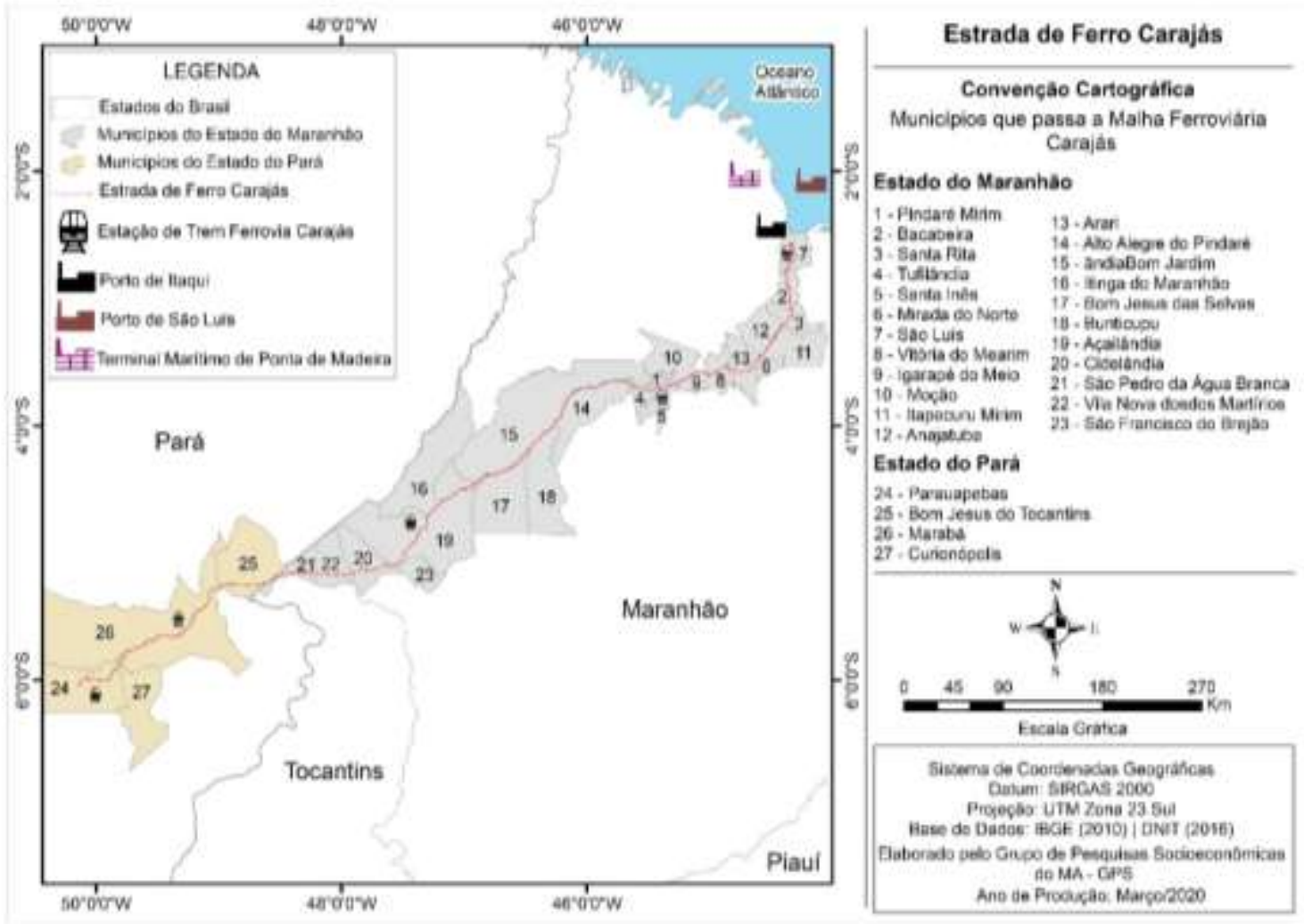

Fonte: IBGE (2010); Brasil (2016).

Como se observa no mapa da malha ferroviária do Maranhão (Figura 3), a ferrovia Carajás une-se a outras infraestruturas ferroviárias que expõem a materialidade técnica dos fluxos de commodities minerais e agrícolas no território maranhense. Junta-se à Ferrovia Norte-Sul (cuja construção teve início em 1987); à ferrovia Transnordestina, subsidiária da Companhia Siderúrgica Nacional (CSN); e, mais recentemente, à ferrovia destinada ao transporte de pasta de celulose (concluída em 2015), fruto do megaempreendimento do grupo Suzano. O projeto da linha férrea transnordestina é da década de 1980 e faz parte da Malha Nordeste, da antiga Rede Ferroviária Federal S.A. (RFFSA), para interligar os portos de Eliseu Martins, no Piauí, a Suape, em Pernambuco.

As cidades de São Luís, Açailândia, Balsas, Estreito, Imperatriz e Porto Franco assumem importância no estado, entre outros fatores, não apenas pelas suas capacidades produtivas, mas por permitirem, através dos seus nós de transportes, maior fluidez e mobilidade do capital no Maranhão, principalmente de commodities agrícolas e minerais.

Os investimentos públicos e privados em projetos agro-minero-exportadores nessas cidades são diversos e se ancoram, fortemente, na modernização dos transportes. Em Açailândia, destaca-se o transporte de ferro-gusa produzido nas indústrias siderúrgicas ou "guseiras". Em Balsas e Porto Franco, as conexões destacam-se pelo transporte de óleo, farelo de soja e soja em grão. Já a cidade de Estreito destaca o transporte da produção 
sucroalcooleira proveniente da Maity Bioenergia. E Imperatriz sobressai-se, a partir de 2014, com seu ingresso na exportação de pasta de celulose.

Figura 3 - Malha ferroviária do Maranhão
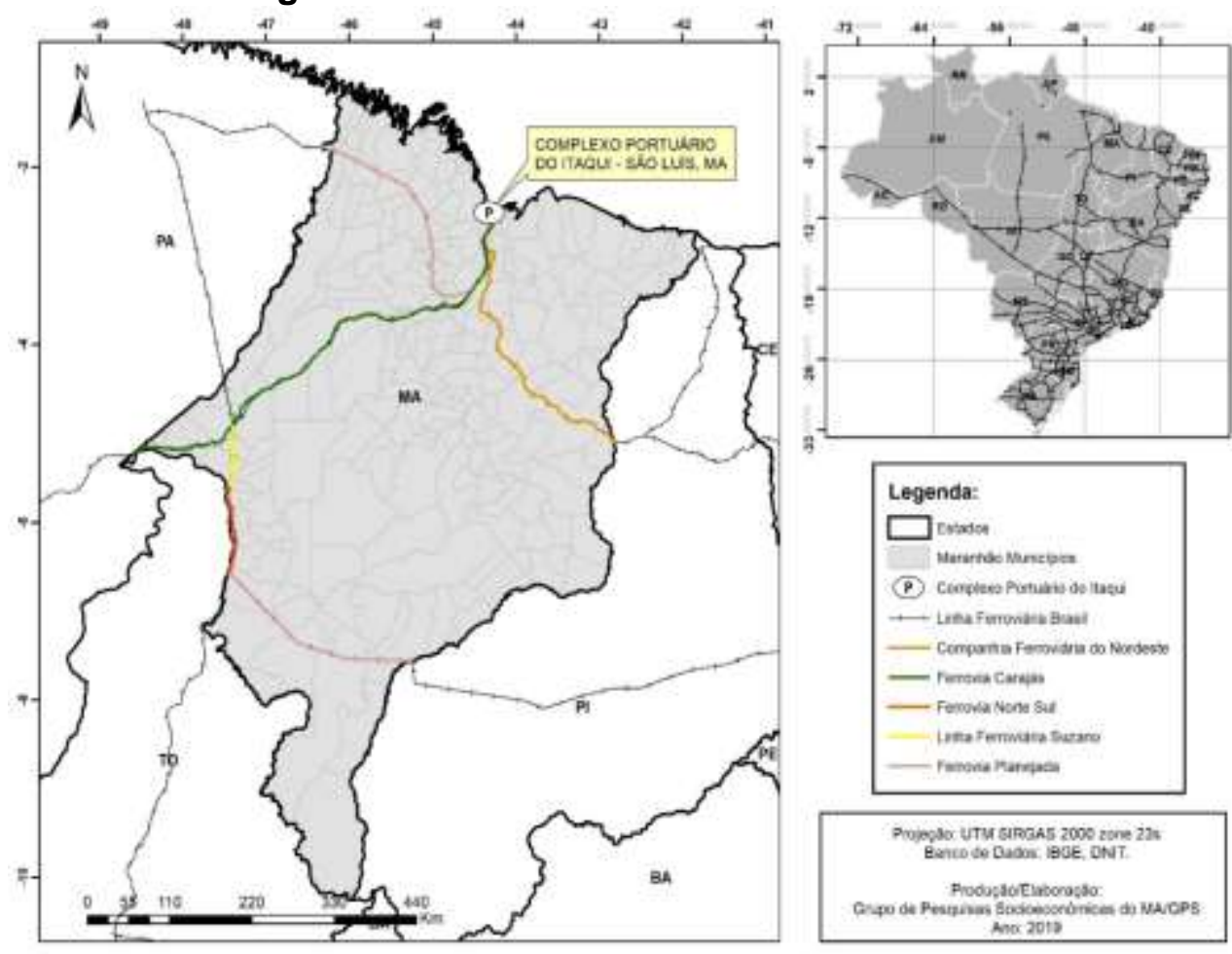

Fonte: IBGE (2010); Brasil (2016).

De forma geral, destacam-se investimentos em "guseiras"; aciarias; produção de cimento e calcário; plantio de florestas, no complexo celulósico; e compra de terras, ampliação de áreas e indústrias de beneficiamento, no complexo da soja. $\mathrm{Na}$ área de logística, os investimentos concentram-se na duplicação de ferrovias, construção e ampliação de complexos portuários. As fontes de financiamento são diversas, inclusive estatais (BNDES), mas também próprias, de bancos e fundos de investimentos (MESQUITA et al., 2015).

Além da ferrovia Carajás, os investimentos e parcerias público-privadas possibilitaram, nas últimas três décadas, o avanço da malha ferroviária maranhense (Figura 3), a exemplo da Companhia Ferroviária do Nordeste, Ferrovia Norte-Sul e, mais recentemente, a linha ferroviária Suzano.

A "integração" econômica proporcionada pelas infraestruturas de transportes no Maranhão deve, portanto, ser pensada principalmente sob o aspecto da mercadoria, e, nesse sentido, os modais de transporte cumprem sua função estratégica, que é transportar commodities agrícolas e minerais, com vistas à exportação, em um processo de modernização que tem no avanço do agronegócio o seu principal desdobramento. 
Historicamente, as infraestruturas ferroportuárias assumem os caminhos necessários para a inserção do Maranhão no mercado global das economias de escala.

\section{COMMODITIES AGROFLORESTAIS, DINÂMICA ECONÔMICA E DEMANDA POR INTEGRAÇÃO MODAL}

A expansão da silvicultura do eucalipto no Maranhão reflete o modelo de desenvolvimento capitalista de produção rural no Brasil, caracterizado, principalmente, pela fusão de dois agentes, o capitalista e o proprietário de terra. Essa unificação de papéis também é um dos resultados da expansão da fronteira agrícola maranhense, iniciada na década de 1970, e passou por significativa ampliação no século XX, como explica Oliveira (1993, p. 186):

A política de incentivos fiscais da Sudene e da Sudam foram os instrumentos de política econômica que viabilizaram esta fusão. Dessa forma, os capitalistas urbanos tornaram-se os maiores proprietários de terra no Brasil, possuindo áreas com dimensões nunca registradas na história da humanidade.

A inserção do eucalipto no Maranhão deu-se, inicialmente, como subproduto dos grandes projetos minerometalúrgicos. A priori, a finalidade era produzir combustível para alimentar as caldeiras de ferro-gusa, produzido a partir do minério, do Projeto Carajás, e do alumínio, da Alumar. Dada a demanda pela produção, o plantio de eucalipto avançou no estado a partir da década de 1980.

Nas duas décadas seguintes (1990 e 2000), o plantio foi intensificado visando outro projeto industrial e a produção de pasta de celulose para exportação, neste caso, o projeto Celulose do Maranhão (Celmar). Embora tal iniciativa não tenha se consolidado, a base plantada oriunda das especulações sobre sua instalação, somada às bases de propriedade da Vale (antiga CVRD), permitiram a implantação real de outro projeto dessa natureza: o grande projeto Suzano Papel e Celulose, em 2008, na cidade de Imperatriz (OLIVEIRA, 2019).

Uma das principais características da produção agroflorestal é a imensa demanda por área plantada, para que seja contínua e intensa a rotação de cultura no período de sete anos necessários para o eucalipto atingir o ponto de corte. Por isso, houve um rápido aumento de áreas plantadas, terras prontas para o plantio e arrendamentos. Houve uma tipificação a partir do eucalipto, em especial na porção amazônica do Maranhão, como é possível observar no gráfico a seguir (Figura 4).

Embora se acredite que os dados reais sejam superiores aos oficiais, é expressivo o aumento no quantitativo de áreas plantadas em um período de 15 anos. Em 2005, a base 
plantada resultante da Celmar e da cadeia siderúrgica estadual era de 60.740 mil hectares, aumentando para 111.120 mil hectares, em 2008, ano do início das obras de construção da unidade da Suzano em Imperatriz. O número chega a 239.078 mil hectares plantados, em 2019, um aumento de 398\% em relação a 2005.

Figura 4 - Maranhão: Evolução de áreas destinadas ao plantio de eucalipto em hectares

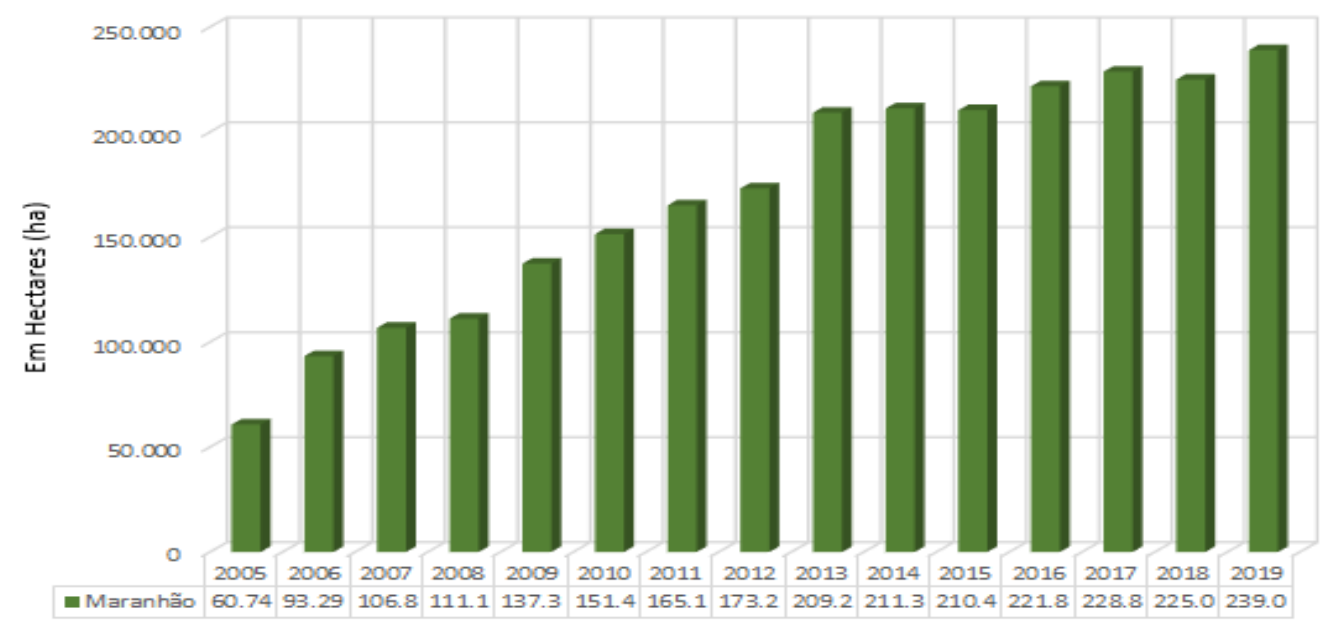

Fonte: IBÁ (2020).

Considerando a busca por integração modal que a ampla cadeia produtiva de papel e celulose exige, é fundamental compreender que a continuidade na circulação do capital só pode ser assegurada mediante a criação ou apropriação de um eficiente sistema de transportes em rede, espacialmente integrado e organizado em torno de centros urbanos. A velocidade também é fundamental, uma vez que a compressão espaço-tempo não depende necessariamente da distância entre produtor e consumidor, mas do tempo que a mercadoria leva para chegar ao mercado (HARVEY, 2013).

O transporte de commodities agroflorestais, especificamente, necessita de que toda a sua cadeia produtiva consiga transportar, com rapidez e eficácia, os diversos insumos até as etapas do processo produtivo e a mercadoria até o consumidor final. Nesse caso, o principal insumo é o eucalipto como matéria-prima até se tornar mercadoria final, ou seja, pasta de celulose. Para ser vendida passando pelo Porto do Itaqui, a pasta passa por inúmeras etapas extremamente dependentes da velocidade de circulação, e a cada etapa produtiva corresponde uma especialização dos transportes.

A Figura 5 apresenta a conectividade sistêmica entre os fixos e os fluxos na reorganização espacial da produção de commodities agroflorestais. A distribuição de fazendas produtoras de eucalipto tende a se concentrar inicialmente na microrregião de Imperatriz, não apenas pela proximidade da unidade fabril da Suzano, mas por ser a área de 
porção amazônica do Maranhão, onde há grande potencial hídrico e concentração de terras baratas.

Figura 5 - Integração da produção e do transporte de eucalipto no Maranhão
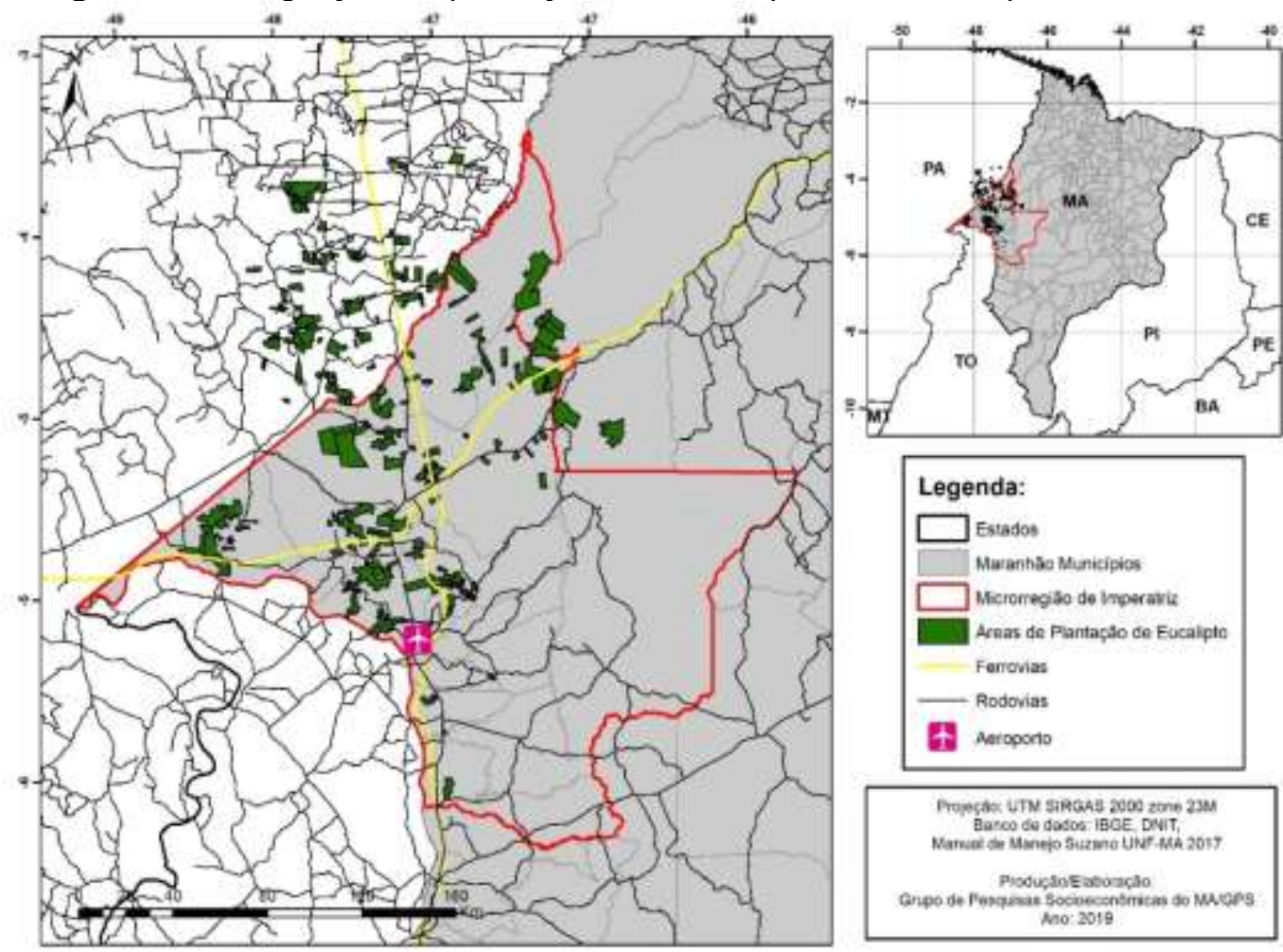

Fonte: IBGE (2010); BRASIL (2016).

Desse modo, a mobilidade do capital em forma de mercadoria ocorre dentro de uma estrutura em eterna modificação, pois o custo e as distâncias podem ser alterados pelo desenvolvimento dos meios de transportes, relativizando as distâncias geográficas. Para isso, é fundamental que haja uma apropriação não só dos meios de transportes, mas também das infraestruturas, de modo a possibilitar uma mobilidade rápida e eficaz. Mesmo com limitações, integram-se a esse processo as rodovias federais BR-010, BR-222, BR-135 e BR-226, e as estaduais MA-125, MA-122, MA-280, MA-335, MA-006, MA-138, MA-276, MA-334 e MA-132, dentre outras.

Atualmente, o corte do eucalipto transportado por essas estruturas é feito com máquinas Feller-buncher e Harverster, que descascam e cortam os troncos das árvores em toras de seis metros, o que acelera a produção. As toras são transportadas até a fábrica em caminhões tritrem (Figura 6); cada caminhão leva, em média, 50 toneladas de madeira. Entretanto, desde 2019, a Suzano já opera também com hexatrens, ampliando vertiginosamente a capacidade de transporte. 
Figura 6 - Integração no transporte de eucalipto/pasta de celulose no Maranhão
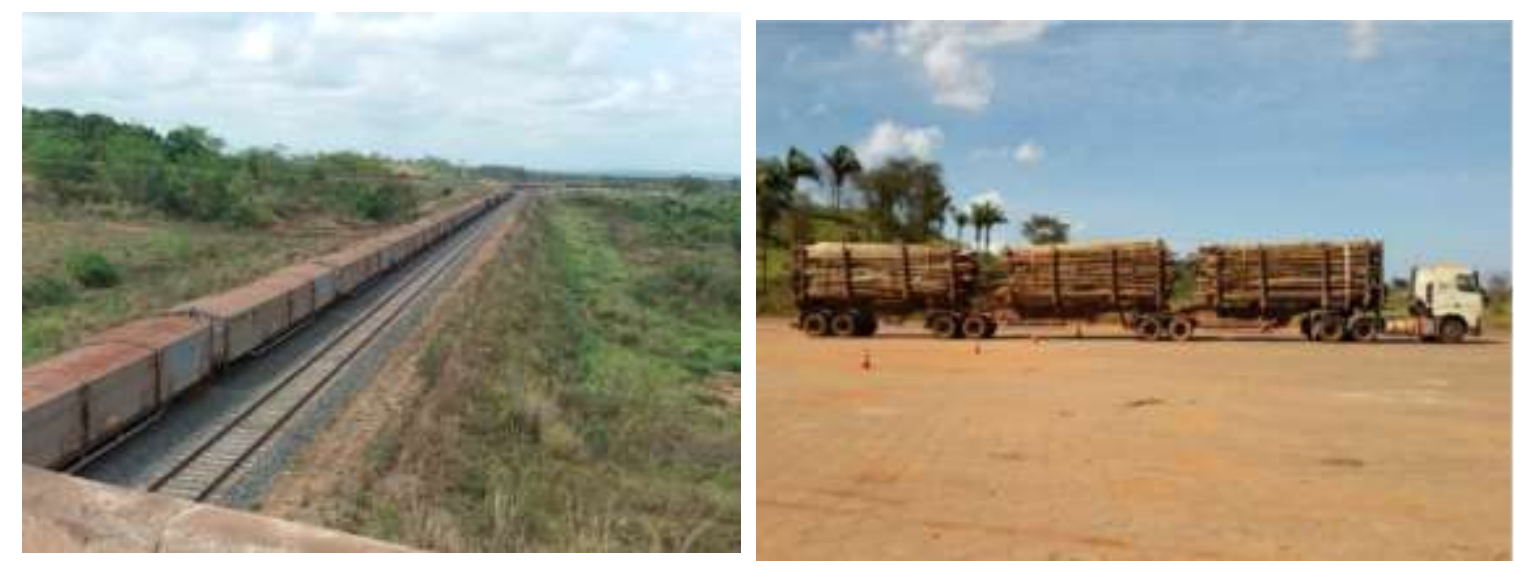

Fonte: Oliveira (2019).

Assim, a mercadoria final, a pasta de celulose, é transportada, via modal ferroviário, até o litoral do estado, de onde é exportada. Desde 2016, foi concluído o trecho ferroviário que liga a fábrica da Suzano até o ponto de conexão Pequiá, na cidade de Açailândia, por onde o produto segue, via ramal Norte-Sul, até o litoral, de onde é transportado pelo Porto do Itaqui.

Harvey (2013) destaca que as reduções no custo e no tempo do movimento, junto a melhorias na regularidade e confiabilidade dos serviços de transporte, tem a ver com o desenvolvimento das forças produtivas que buscam cada vez mais criar mecanismos para diminuir as rugosidades espaciais. Isso remete à atual expansão no transporte agroflorestal, marcada pela inserção do hexatrem, carreta de 52 metros, especialmente desenvolvida para a Suzano, para uso em estradas de terra, com maior capacidade de carga, menos custos operacionais com peças e menor consumo de combustível.

Embora seja problemático, como afirma Harvey (2013), haver concorrência entre transportes quando a questão é infraestrutura (ferrovias e rodovias, por exemplo), o mesmo não ocorre com os veículos de transporte. Isso faz com que sejam criadas circunstâncias que acirrem os processos de competição e, consequentemente, de diminuição de custos e velocidade de transportes, tais como: aumento do número de caminhões, aviões, cargueiros ofertando frete, e mesmo o aumento da modalidade de formas precarizadas de trabalho, como a terceirização do transporte de eucalipto feito em caminhões de motoristas autônomos, prática comum no segmento.

O fluxo de matéria-prima para a produção de pasta de celulose aumentou não apenas as áreas de plantio de eucalipto, mas também o número de caminhões no estado. $O$ gráfico a seguir (Figura 7) apresenta a rápida evolução desse meio de transporte em Imperatriz, no Maranhão. Em 2008, quando da implantação da Suzano, havia 97 caminhões-tratores com emplacamento do município, segundo dados do Departamento Nacional de Trânsito (DENATRAN, 2020); esse quantitativo - sem considerar caminhões-tratores com 
emplacamento de outros estados, mas que atuam no Maranhão - saltou para 622, em 2018, um aumento de quase $650 \%$. No mesmo período, em todo o estado, houve um aumento de 942 caminhões cadastrados para 4.479 caminhões, uma expansão de $475 \%$ na frota estadual.

Figura 7 - Evolução de caminhões-tratores no Maranhão

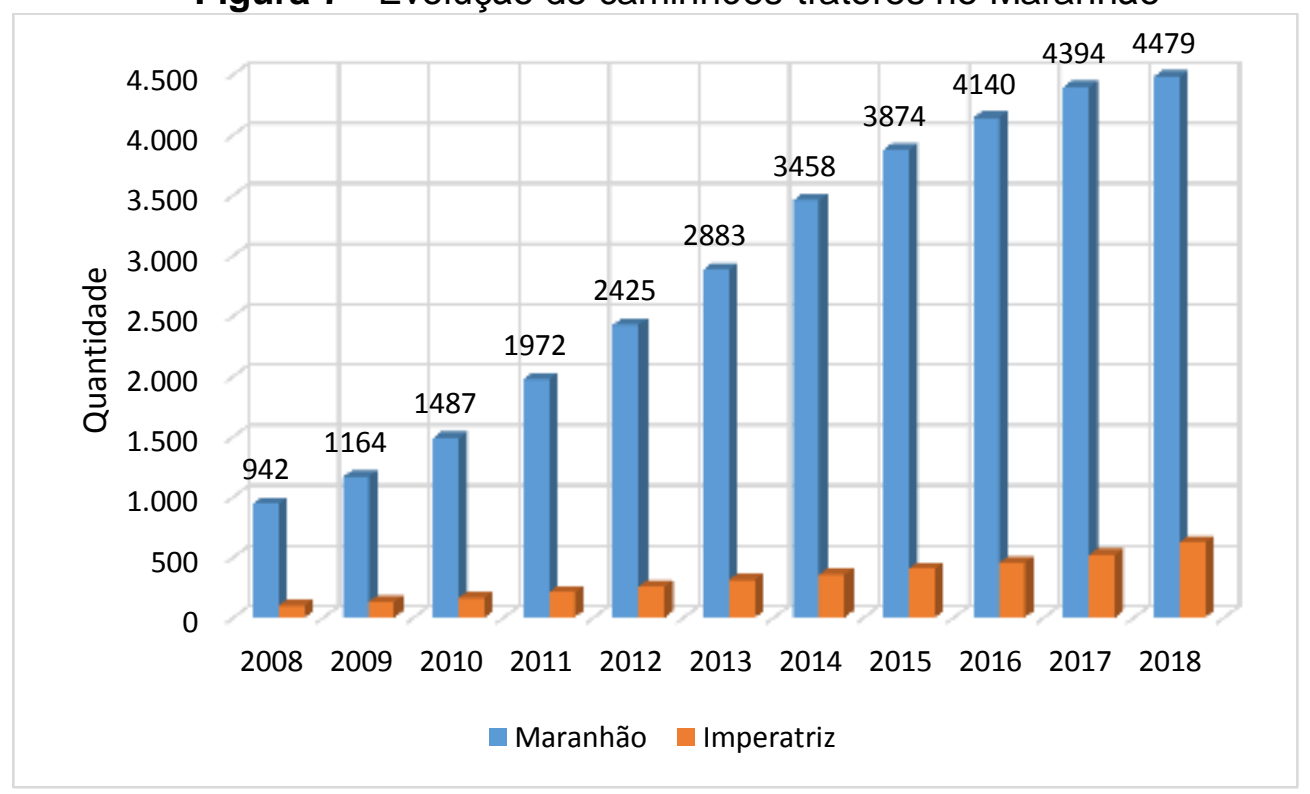

Fonte: Denatran (2020).

Visando conectar pontos e fazer circular a produção, as infraestruturas e os meios de transporte criam, no Maranhão, um emaranhado de redes orientadas para atender, em especial, a circulação de bens, serviços e mercadorias. Tais redes conectam-se nos diferentes modais, em diversos estágios da produção, até chegarem à exportação no Porto do Itaqui. Assim, o porto representa não apenas um elemento de modernização das dinâmicas econômicas regionais, mas também um indicativo da participação dos principais produtos exportados e da inerente especialização produtiva que o estado assume diante do mercado global.

No gráfico (Figura 8), pode-se observar que a celulose só começou a ser produzida para exportação a partir de 2014 , saltando de 889.198 mil toneladas, naquele ano, para 1.436 .630 milhão de toneladas no ano de 2018, quase o dobro do volume produzido. Em 2018, a produção de celulose foi superior à de outras commodities com maior peso histórico nas exportações do estado, como as de ordem mineral — por exemplo, manganês, ferrogusa e cobre - e ficando atrás apenas da soja, que, nesse ano, exportou um total de 8.491.504 milhões de toneladas.

Outras commodities tiveram baixas na produção, como manganês, ferro-gusa e cobre. Em especial, houve drástica diminuição da produção de ferro-gusa e lingotes de alumínio no 
Maranhão. Em ambos os casos, a debilidade concorrencial do ponto de vista do valor da produção e o dumping chinês fizeram com que, na última década, três das cinco siderúrgicas do município de Açailândia e a Alumar, em São Luís, encerrassem suas atividades.

Figura 8 - Principais commodities exportadas através do Porto do Itaqui (2008 - 2018)

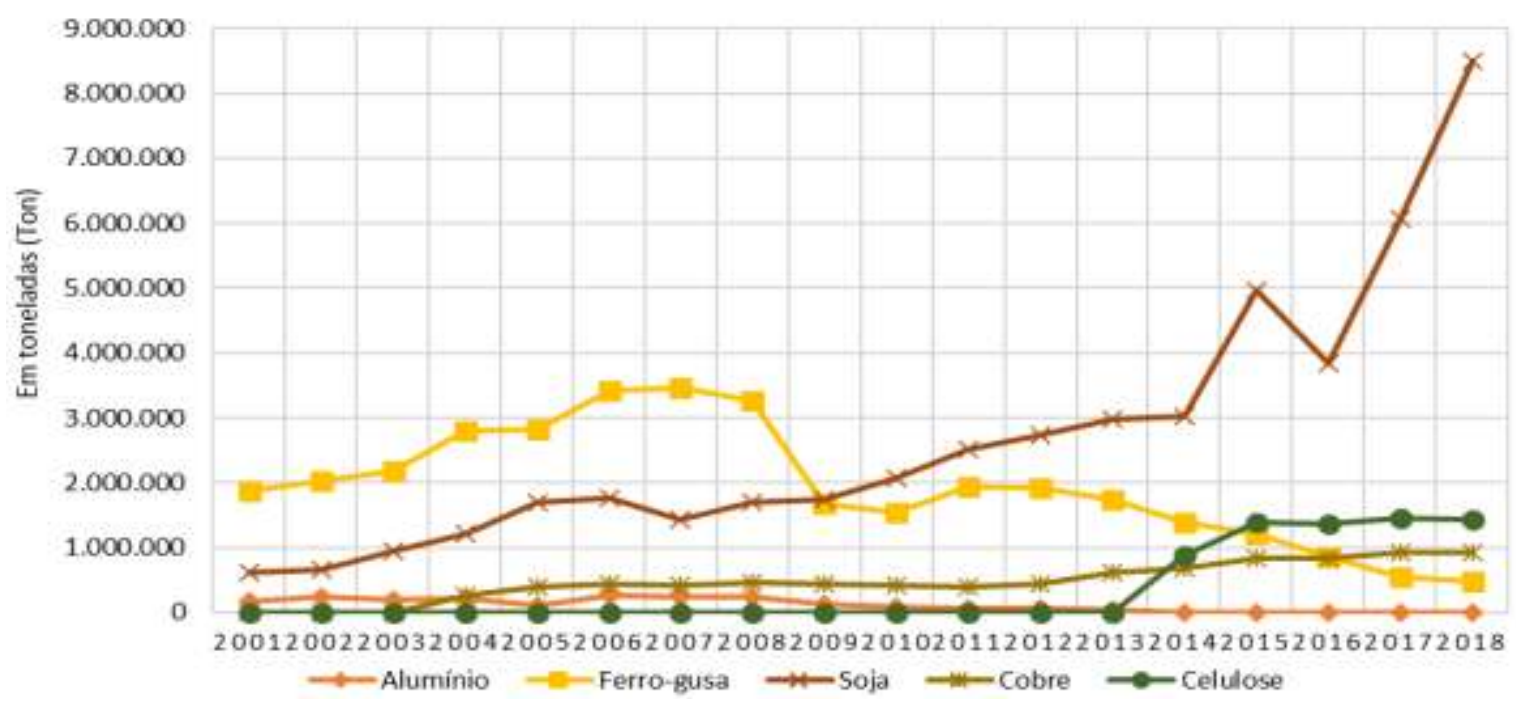

Fonte: EMAP (2020).

Nas duas últimas décadas, a economia maranhense cresceu em velocidade expressiva, conforme Figura 9, sobretudo em relação à média nordestina e à média nacional, e a exportação de commodities minerais e agrícolas (alumínio, ferro-gusa, manganês, cobre, etanol, minério de ferro, trigo, soja e celulose) foi decisiva para conectar o Maranhão à economia global, com destaque para a soja, que se configura como principal componente na balança comercial do estado, seguida da pasta de celulose, que, já no seu segundo ano de exportação, passou a ser a segunda commodity de maior peso econômico no estado.

Assim, nas últimas quatro décadas, os processos agro-minero-exportadores mantiveram-se no foco da dinâmica econômica do Maranhão, da mesma forma que ocorrera no passado, inclusive também acarretando grande ônus social e ambiental para o estado; tal padrão de reprodução do capital apresenta-se como principal foco de especialização produtiva regional. Essas características da dinâmica econômica são indissociáveis da questão do espaço, logo, também dos transportes. 


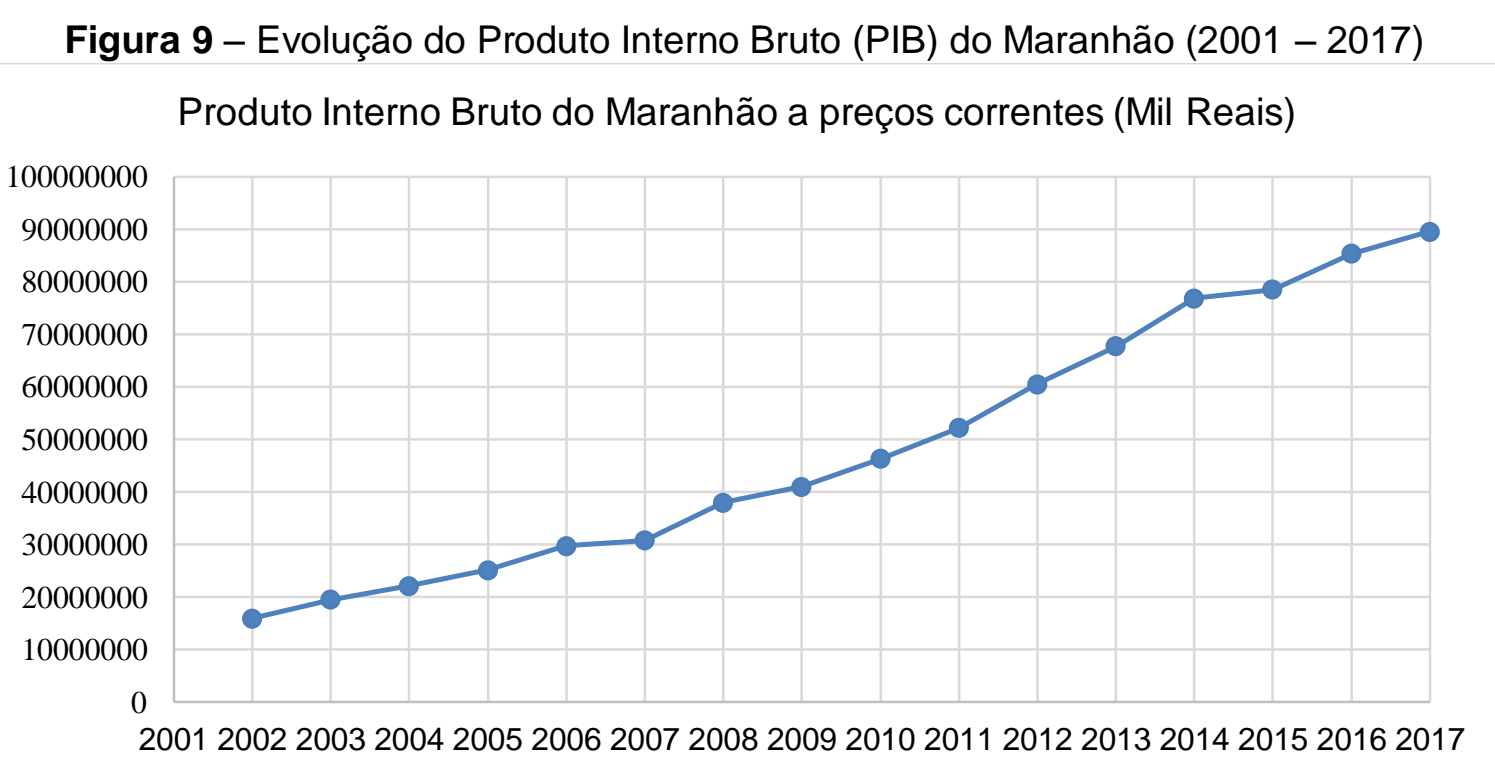

Fonte: IBGE (2020).

\section{CONSIDERAÇÕES FINAIS}

Na década de 1970, a rodovia Belém-Brasília teve papel preponderante nas transformações econômicas que se sucederam no Maranhão, principalmente na sua porção amazônica. A rodovia foi responsável por intensificações na expansão da fronteira agrícola, resultando em concentração de terras, e por transformações na economia através da circulação de matéria-prima e outras mercadorias entre a região e o centro-sul industrial do país.

Esses aspectos forneceram as bases para a implantação do Grande Projeto Carajás, no Pará, com forte impacto no Maranhão, sobretudo em relação à modernização e integração ferroportuária. Isso possibilitou não só a exportação de minério, mas a implantação de projetos minerometalúrgicos, como a Alumar, em São Luís, e o aglomerado industrial produtor de ferro-gusa, em Açailândia.

Assim, no fim da década de 1980, com grande ônus social e ambiental, sistematizouse na região um modelo de desenvolvimento econômico baseado na produção e exportação de commodities à luz de um capitalismo "moderno", estabelecido também sobre os modais de transportes.

No Maranhão de hoje, as commodities de origem agrícola, em especial pasta de celulose e soja, assumem centralidade econômica na dinâmica produtiva regional do estado. No bojo dessa centralidade, elas reestruturam as bases da economia de escala e consolidam o modelo produtivo iniciado no passado, voltado para a exportação de produtos de baixo valor agregado; iniciado também por grandes projetos minerometalúrgicos, e agora pelos grandes projetos agroindustriais. 


\section{REFERÊNCIAS}

ARRAIS, Tadeu Alencar; CASTILHO, Denis; AURÉLIO NETO, Onofre Pereira. Integração nacional e fragmentação regional: o sentido territorial da BR-153 no centro-norte brasileiro. Geographia, Niterói, v. 18, n. 36, p. 62-85, 2016. Disponível em: https://doi.org/10.22409/GEOgraphia2016.v18i36.a13743. Acesso em: 7 mar. 2020.

BRASIL. Ministério da Infraestrutura. Departamento Nacional de Infraestrutura de Transportes. Infraestrutura rodoviária. Brasília, DF: DNIT, 2016. Disponível em: https://www.gov.br/dnit/pt-br/assuntos/infraestrutura-rodoviaria. Acesso em: 7 out. 2020.

DENATRAN - Departamento Nacional de Trânsito. Volume de veículos por estado da federação. Brasília, DF: DENATRAN, 2020. Disponível em:

https://www.gov.br/infraestrutura/pt-br/assuntos/transito/conteudo-denatran/estatisticasdenatran. Acesso em: 10 mar. 2020.

EMAP - Empresa Maranhense de Administração Portuária. Relatório de movimentação de cargas portuárias no Maranhão. [São Luís]: EMAP, 2020. Disponível em:

https://www.emap.ma.gov.br/public/_files/arquivos/Relat\%C3\%B3rio\%20de\%20Movimenta\% C3\%A7\%C3\%A30\%20de\%20Cargas-\%202001\%20a\%202019_5e5e3d3b1e103.pdf. Acesso em: 10 abr. 2020.

HARVEY, David. Os limites do capital. São Paulo: Boitempo, 2013.

IBÁ - Indústria Brasileira de Árvores. Relatório de produção da silvicultura no Brasil.

Brasília, DF: IBÁ, 2020. Disponível em: https://www.iba.org/dados-estatisticos. Acesso em: 10 mar. 2020.

IBGE. Produto interno bruto dos estados brasileiros. Rio de Janeiro: IBGE, 2020.

Disponível em: https://sidra.ibge.gov.br/. Acesso em: 14 jun. 2020.

IBGE. Infraestrutura de transporte e logística no Brasil. Rio de Janeiro: IBGE, 2010.

Disponível em: https://mapas.ibge.gov.br/tematicos/infra-estrutura-e-logistica. Acesso em: 14 fev. 2020.

KUBITSCHEK, Juscelino. Por que construí Brasília. Brasília, DF: Senado Federal, 2000.

MESQUITA, Benjamin Alvino et al. Formação socioeconômica do estado do Maranhão. In: CASTRO, Edna Ramos; CAMPOS, Índio (org.) Formação socioeconômica da Amazônia. Belém: NAEA/UFPA, 2015. cap. 5, p. 225-319.

MESQUITA, Benjamin Alvino. Notas sobre a dinâmica econômica recente em área periférica: as mudanças na estrutura produtiva do Maranhão. In: CONFERÊNCIA DO DESENVOLVIMENTO (CODE/IPEA), 2., 2011, Brasília, DF. Anais eletrônicos [...]. Brasília, DF: Ipea, 2011. p. 1-15. Disponível em:

https://www.ipea.gov.br/code2011/chamada2011/pdf/area4/area4-artigo33.pdf. Acesso em: 19 out. 2020.

MOTTA, Célia Maria. Um desenvolvimento insustentável. Lutas Sociais, São Paulo, n. 11/12, p. 23-35, jun. 2004. Disponível em: https://ken.pucsp.br/ls/article/view/18693/13890. Acesso em: 7 mar. 2020.

OLIVEIRA, Allison Bezerra. Indústria de celulose e o avanço da silvicultura do eucalipto na fronteira agrícola da Amazônia maranhense. Geosul, Florianópolis, v. 34, n. 71, p. 301-327, abr. 2019. Dossiê Agronegócios no Brasil. Disponível em: http://doi.org/10.5007/19825153.2019v34n71p301. Acesso em: 7 mar. 2020.

OLIVEIRA, Francisco. Elegia para uma re(li)gião: Sudene, Nordeste, planejamento e conflito de classes. Rio de Janeiro: Paz e Terra, 1993. 
PRADO JÚNIOR, Caio. História econômica do Brasil. São Paulo: Brasiliense, 1945.

SICSÚ, Abraham Benzaquem; LIMA, João Policarpo Rodrigues. Fronteiras agrícolas no Brasil: a lógica de sua ocupação recente. Nova Economia, Belo Horizonte v. 10, n. 1, p. 109-138, jul. 2000. Disponível em:

https://revistas.face.ufmg.br/index.php/novaeconomia/article/view/2145/1123. Acesso em: 7 fev. 2020.

SUZIGAN, Wilson. Indústria brasileira: origem e desenvolvimento. São Paulo: Hucitec; Campinas: Unicamp, 2000.

\section{AGRADECIMENTOS}

Este trabalho é resultado de pesquisa desenvolvida com auxílio financeiro concedido pela Fundação de Amparo à Pesquisa e ao Desenvolvimento Científico e Tecnológico do Maranhão (FAPEMA), sob a coordenação do Grupo de Pesquisas Socioeconômicas do MA - GPS/UEMASUL. 